\title{
A Survey of TDMA-based MAC Protocols for Vehicular Ad Hoc Networks
}

\author{
Siman Emmanuel, Ismail Fauzi Bin Isnin, Mohd. Murtadha Bin Mohamad
}

\begin{abstract}
MAC design in a vehicle network is a challenging task due to high node speed, frequent topology changes, lack of infrastructure, and different QoS requirements. Several medium access control protocols based on Time Division Multiple Access (TDMA) have recently been suggested for VANETs in an effort to guarantee that all cars have sufficient time to send safety messages without collisions and to decrease the end-to-end delay and the loss ratio of packets. The reasons for using the collision-free media access control paradigm in VANETs are identified in this document. We then present a new topology-based classification and provide an overview of the MAC protocols suggested for VANETs based on TDMA. We concentrate on these protocols 'features as well as their advantages and constraints. Finally, we provide a qualitative comparison and address some open problems that need to be addressed in future studies to enhance the efficiency of TDMA-based MAC protocols for vehicle-to-vehicle $(\mathrm{V} 2 \mathrm{~V})$ and vehicle to infrastructural (V2I) communications.
\end{abstract}

Keywords: VANET, IEEE 802.11p, DSRC, MAC protocol, TDMA.

\section{INTRODUCTION}

Vehicular Ad hoc Networks (VANETs) are primarily designed to improve safety on roads. They can also be used to improve traffic management conditions and to provide on-board infotainment such as Internet access, video streaming, etc [1]. VANETs are an example of Mobile Ad hoc Networks (MANETs) but with their own specificities: high node mobility with constrained movements and the mobile nodes have ample energy and computing power. In VANETs, communications can either be between vehicles V2V (Vehicle To Vehicle) or between vehicles and road side units V2I (Vehicle to Infrastructure). The applications for V2V and V2I can be divided into the following three services: safety services, traffic management and user-oriented services.

Safety services have special requirements in terms of quality of service. In fact, bounded transmission delays as well as low access delays are mandatory in order to offer the highest possible level of safety. At the same time, user-oriented services need a broad bandwidth. Medium Access Control will play an important role in satisfying these requirements.

In VANETs, the nodes share a common wireless channel

Revised Version Manuscript Received on April 19, 2019.

Siman Emmanuel, Computer Science, Federal University Wukari, Taraba, Nigeria. \& Computer Science, Faculty of computing, Universiti Teknologi Malaysia, Johor, Malaysia. (Email: emmasiman2017@gmail.com)

Ismail Fauzi Bin Isnin, H Computer Science, Faculty of computing, Universiti Teknologi Malaysia, Johor, Malaysia.

Mohd. Murtadha Bin Mohamad, Computer Science, Faculty of computing, Universiti Teknologi Malaysia, Johor, Malaysia.

using the same radio frequencies, so inappropriate channel use can lead to collisions and bandwidth waste. Channel sharing is therefore the main problem in the quest for high-quality service. Medium Access Control (MAC) systems must be intended to effectively and fairly share the medium between the distinct nodes. However, traditional wireless MAC protocols are not suitable for use in VANETs due to the special characteristics of VANETs, which either leads to the adaptation of these traditional MAC protocols or to the design of new mechanisms, [5]. Generally, one of two wide classifications of MAC protocols is: contention-based and contention-free. Each node can try to access the channel when it has data to be transmitted using the carrier sensing mechanism in contention-based protocols. Several nearby nodes can sense a free channel and thus decide to simultaneously access and transmit their information, causing collisions at the target nodes, [6]. Contention-free MAC protocols attempt to prevent this by at any specified moment assigning access to the channel to just one node in a neighborhood. Contention-based protocols do not require a predefined timetable, each node will compete for access to the channel when it needs to be transmitted without any guarantee of achievement.

This can trigger issues such as packet loss or big delay in accessing apps in real time. Contention-free protocols, on the other hand, can provide limited delays for real-time applications, but require the regular exchange of control messages to maintain the schedule table and require time synchronization between all the network nodes. MAC protocols must give an effective broadcast service with predictable limited delays in order to provide QoS and decrease collisions in VANET networks. They also have to deal with frequent changes in topology, different node spatial densities and the hidden / exposed node issue. Multi-hop communication and nodes (cars) must be supported going in opposite directions. The significance of these problems was verified by developing a particular IEEE standard to support VANETs. The IEEE $802.11 \mathrm{p}$, the emerging standard used to enable vehicle communication, is a contention-based MAC protocol, using a priority-based access scheme using Enhanced Distributed Channel Access (EDCA) and Carrier Sense Multiple Access with Collision Avoidance (CSMA / CA) mechanisms in [9]. The IEEE 802.11p standard does not provide limited communication delay with a reliable broadcast mechanism. In VANETs, which are specifically designed to improve road safety, this disadvantage is 
particularly important. It is therefore a particularly difficult job to design an effective MAC protocol that meets the QoS demands of VANET apps.

An evolving field of VANET studies is TDMA-based MAC protocols where time is split into slots and only one car can access the channel at each slot, in [10]. All cars in TDMA use the same frequency channel at a separate moment without any code sequence. This implies the transmitter and the receiver must be synchronized with the frequency. Unlike the FDMA system, the TDMA method guarantees that they will not experience interference from other concurrent transmissions in [4], which may suffer from interference between cars using the same frequency band and begin transmitting at the same moment. In addition, TDMA can support I2V communication effectively as it is possible to use fixed RSUs to generate and handle the TDMA slot booking timetable. Another significant characteristic of the TDMA system is that it enables allocation to separate cars of a distinct amount of time slots. This implies that, by concatenating or rescheduling time slots based on access priority, the bandwidth resources can be allocated on demand to separate cars. However, by offering collisions with TDMA, a collision-free transmission with limited access delay, can happen in essence, and TDMA is better adapted to VANET demands. MAC protocols have drawn a lot of attention recently, particularly those based on the TDMA method, and many protocols have been suggested in [11]. While these protocols can provide deterministic access time without collision, they must be conscious of the slot distribution of the neighbors in order to function effectively. Moreover, most of them use real-time systems that provide location and time data such as the Global Positioning System (GPS) that allows them to synchronize the cars that communicate. However, due to the high mobility of vehicles in VANETs that can affect the performance of these protocols in [13], many problems arise. Therefore, to avoid collisions, the scheduling mechanism in TDMA protocols should take into account the mobility features of VANETs.

\section{LITERATURE REVIEW}

This section presents in the vehicle ad hoc network a structured literature review related to the TDMA-MAC protocol. TDMA-based MAC protocol guaranteeing efficient broadcasting service and quality of service (QoS) for inter-vehicle communications and solving hidden / exposed terminal problems caused by random access in multi-hop network architecture[3][14]. Unlike the IEEE 802.11p standard, it is a single channel protocol that is not suitable for dedicated short-range communication (DSRC) using seven DSRC channels and assigning time slots based on vehicle direction to reduce vehicle-to-vehicle collisions in, [15][2]. However, for the control channel $(\mathrm{CCH})$ and service channels (SCHs), it employs two half-duplex transceivers, respectively. Many contention-free TDMA MAC protocols have recently adopted cluster-based architecture because with the help of cluster head $(\mathrm{CH})$ they can provide effective topology control, fair channel access within each cluster and minimize intra-cluster and inter-cluster transmission collisions in [16].

Clustering-based multichannel MAC (CBMMAC) protocol uses both contention-free and contention-based access mechanisms and supports applications that are both safety-relevant and non-safety service. However, there are two half-duplex transceivers for each vehicle, [17][18]. A cluster-based MAC (TC-MAC) multichannel TDMA protocol combines a cluster-based centralized management method with a new dynamic TDMA slot booking mechanism. In contrast to the standard IEEE 1609.4 structure, its frames are not divided into two segments [8]. By using SCH during the CCHI, TC-MAC can improve the use of bandwidth. It is designed for simple one-way highway scenarios, however, and the likelihood of collisions with transmission is very high for bidirectional expressway scenarios and urban scenarios where collision problems can easily occur. The critical review of the literature providing the necessary background information and the basis for the material presented in the following sections.

\section{Dedicated Short Range Communication (DSRC)}

The Dedicated Short Range Communication Specification is based on the present IEEE 802.11p wireless connectivity standards, with modifications to the PHY and MAC layers to ensure reliable and low latency in car communication, $5 \mathrm{GHz}$ Dedicated Short Range Communication (DSRC) and Wireless Access Vehicle Environment (WAVE) IEEE 1609 for safety and networking., [19]. The U.S. Federal Communications Commission (FCC) allocates $75 \mathrm{M}-\mathrm{Hz}$ of bandwidth resources in the $5.9 \mathrm{G}-\mathrm{Hz}$ band, specifically for inter-vehicle (i.e., V2V or V2I) communication in VANETs, commonly known as dedicated short-range communication (DSRC). DSRC splits the spectrum of $75 \mathrm{M}-\mathrm{Hz}$ into seven frequency bands, including one control channel $(\mathrm{CCH})$ for the transmission of safety or control texts and six service channels (SCHs) for the transmission of service texts in figure 1. Europe, Japan and China have suggested their own vehicle network norms and communication protocols. Based on the network of cellular LTE, S. Chen, Hu, Shi, \& Zhao, S. In the VANET environment, [20] suggested LTE-V as a alternative for V2X. The program in China is considered to be a more appropriate vehicle communication network technology. Europe has assigned a dedicated $5855-5925 \mathrm{MHz}$ channel for DSRC, while Japan has selected $755.5-764.5 \mathrm{MHz}$ as a specialized communications band for smart transport systems. The aim of this Specification is to create Smart Transportation Systems (ITS) to enhance ITS communications architecture for vehicle-to-vehicle (V2V) and vehicle-to-infrastructure (V2I) traffic management, transportation safety and mobility.

The Dedicated Short-Range Communication Technology was developed for short distance mobile vehicle applications. More specifically, the short distant communication takes place between the on-board unit (OBU) on the vehicle and the beacon in the (fixed) road environment. This basic system shows all the elements described in the idea of the DSRC. DSRC packet messaging technique was created to operate at $5.8 \mathrm{GHz}$ frequency using typically $10 \mathrm{MHz}$ bandwidth with 
information rates of up to $2048 \mathrm{Mbps}$. This is the European standard accepted by the European Standards Committee (CEN), [15][21]. However, the separate requirements (used frequency, amount and length of channels, etc.) were used in separate nations and continents. For example, the U.S. DSRC protocol uses $5.9 \mathrm{GHz}$ frequency split into seven $10 \mathrm{MHz}$ bands. Dedicated Short-Range Communications (DSRC) is a collection of initially intended procedures for Intelligent Transportation Intelligent Communications, [22], figure 1. Intelligent Transportation Systems (ITS) was instrumental in reducing daily commute times and reducing congestion in intersection traffic. Traditional ITS uses, [23], smart intersections capable of detecting vehicles using loop detectors, magnetic detectors or cameras and adapting the decision on traffic light accordingly. Such solutions are very expensive and in most cities over the past three decades have therefore not scaled well. Dedicated short-range communication (DSRC) technology is a very attractive new technology.

According to [24], the DSRC system has two main operating modes: a broadcast mode and a peer-to-peer mode. A typical DSRC device includes two independent radios: one dedicated to receiving and broadcasting on the public safety broadcasting channel (i.e. channel 172) and one dedicated to peer-to-peer communications on the control and general service channels. Although different types of traffic safety related messages may be broadcast by the public safety channel, the BSM is considered representative of the size and frequency of most DSRC safety messages. The basic frame format for broadcast security related DSRC messages is similar, but the associated packet lengths will vary.

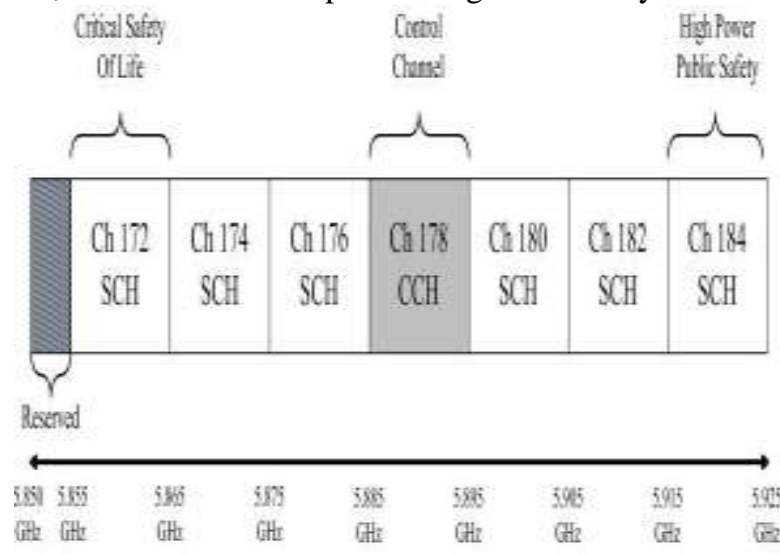

Figure 1: DSRC Framework

The IEEE 802.11p standard is a single channel protocol that is not suitable for dedicated short-range communication (DSRC) in multichannel scenarios. Hadded et al. (2015) Based on ADHOC MAC, VeMAC can use the seven DSRC channels and allocate time slots based on vehicle movement direction to significantly reduce transmission collisions between vehicles. However, it uses two half-duplex transceivers respectively for the control channel $(\mathrm{CCH})$ and service channels (SCHs), Figure 1. For VANETs such as ADHOC MAC and VeMAC protocol, multiple access

(TDMA) based MAC protocols are suggested to solve the above problems. ADHOC MAC is a distributed MAC protocol based on TDMA that provides efficient broadcast and service quality (QoS) guarantees for inter-vehicle communication and solves hidden / exposed terminal problems caused by random access in multi-hop network architecture, [7].

\section{Time Division Multi Access (TDMA)}

According to [25], VANETs highlights the weaknesses of regional MAC standards. MAC protocol is responsible for the wireless resource distribution between vehicles. It must ensure that live critical safety messages are delivered with a limited delay. MAC standardization has a setback as the work is based on a contention-based mechanism due to unbounded delay in security messages. Less-based contention mechanism such as CDMA, SDMA and TDMA. TDMA-based MAC solves only a few problems by evaluating the basic idea, operation and performance of these protocols to outline the current status of MAC research for VANETs. Discussing and identifying the limitations of regional standards. It also develops important MAC protocols based on TDM, clearly stating their basic idea, operation and performance, followed by their comparison. VeSOMAC (Vehicle Self Organizing $\mathrm{MAC}$ ): This protocol is proposed to contain free access technique that uses in-band control mechanism where each node shares a bit map with its neighbors, containing slot information. In both synchronous mode and asynchronous mode, it can operate. Improved TCP throughput in this protocol. The results of the simulation are based solely on the highway scenario.

Based on [26] Originally, black-burst (channel jamming signal) was used in wireless networks to inform one-hop neighbors about the channel's use and to prevent collisions by forcing reference nodes. Using the redundancy time at the beginning of time slot, each vehicle sends a black burst after a random delay from the beginning of the reservation slot to inform its neighbors of the time slot's access will. By using the randomly shifted black-burst, a node can detect other nodes that reserve current slot in two-hop range in advance and decide to reserve current slot or re-select another idle slot. After successfully reserving the selected slot, the black-burst part in the subsequent frames will be removed. Black-burst is based on a novelty time slot acquisition scheme for the TDMA / CSMA multi-channel MAC hybrid in VANETs. In this scheme, all contending nodes broadcast a black burst at the beginning of the selected slots to inform others about the access of their selected idle slots within their two-hop range. The proposed access scheme can reduce the number of access collisions significantly. The results of the simulation show the superiority of the scheme in time slot acquisition. However, the performance of BB-MAC is much better than HTC-MAC when the density becomes higher, figure 2 . The proposed slot acquisition scheme, called BB-MAC, can significantly reduce access collisions and speed up time slot acquisition compared to the above-mentioned protocols. This scheme was limited to a vehicle node medium density.

According to [27], provide a reason for the interactive and time-critical distance-bounding phase in which the prover is required to send the response to the verifier as soon as the 
challenge has been received to minimize the delay. In CSMA / CA, however, both RSU and cars must compete on the same channel for transmission opportunity, while at the same moment only one party is permitted to send packages. For example, an RSU and a vehicle will run a distance bounding protocol and more specifically assume that they have already completed the slow phase and will do the bounding phase of the n-rounds distance, then the RSU will send a challenge and start its clock. It is difficult to ensure that the car will be able to send the reply in time as it could be in the queue to transmit data in order to prevent possible collision. The waiting time is not deterministic and can't be pre-measured. As a result, the challenge / response propagating round-trip time can not be correctly obtained from the recorded moment, which fails the range limitation. The implement TDMA to a suggested system in order to prevent this issue. In particular, TDMA operates in a time-slotted structure, i.e. a virtual frame with a set of time slots with the same time period (e.g. $1 \mathrm{~ms}$ ). When the node can send information without collision, each node is allocated at least one time slot in each frame, in figure 2. TDMA is a method used to enable multiple nodes to transmit on the same frequency channel based on the slot researvations as follows

Time Division Multiple Access (TDMA) Slot Reservation

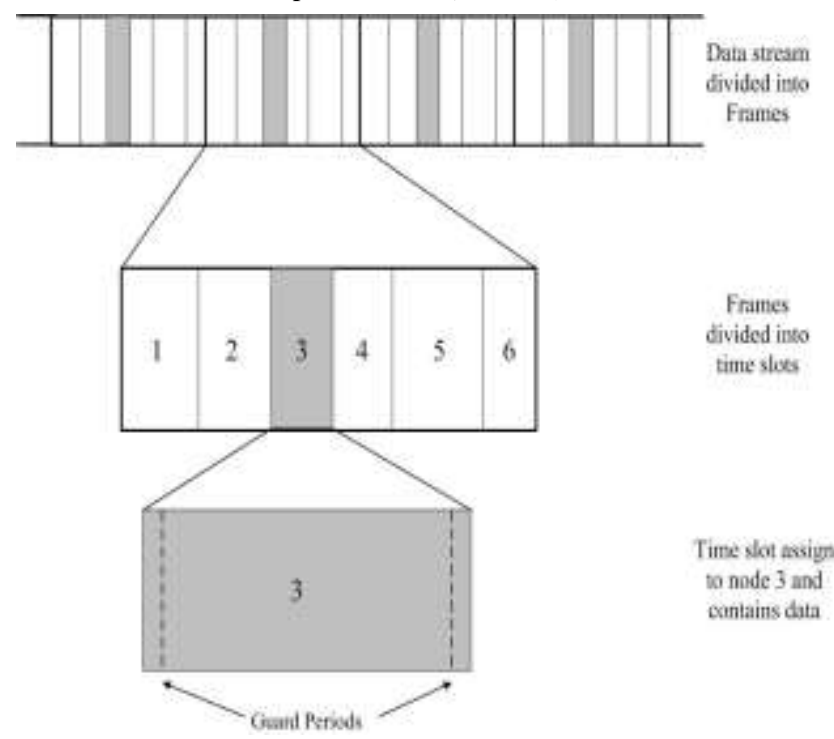

Figure 2: Time Division Multiple Access (TDMA) Slot Reservation

TABLE 1: Qualitative comparison of TDMA-based MAC protocols in VANET

\begin{tabular}{|c|c|c|c|c|c|c|c|c|c|c|c|c|}
\hline & $\begin{array}{l}\text { HTC- } \\
\text { МАC }\end{array}$ & $\begin{array}{l}\text { СТМА } \\
\text { C }\end{array}$ & $\begin{array}{l}\text { TDMA-CS } \\
\text { МA }\end{array}$ & PTMAC & $\begin{array}{l}\text { RCMA } \\
\text { C }\end{array}$ & $\begin{array}{l}\text { FCM- } \\
\text { MAC }\end{array}$ & $\begin{array}{l}\text { EQM- } \\
\text { МАC }\end{array}$ & APDM & $\begin{array}{l}\text { МoMA } \\
\text { C }\end{array}$ & ABC & $\begin{array}{l}\text { VeSOM } \\
\text { AC }\end{array}$ & $\begin{array}{l}\text { BB-MA } \\
\text { C }\end{array}$ \\
\hline $\begin{array}{l}\text { Referenc } \\
\text { es }\end{array}$ & $\begin{array}{l}\text { Nyojen } \\
\text { et al }\end{array}$ & $\begin{array}{l}\text { Hadded } \\
\text { et al }\end{array}$ & $\begin{array}{l}\text { Y. Nguyen et } \\
\text { al }\end{array}$ & Jiang et al & $\begin{array}{l}\text { N. Ngujen } \\
\text { et al }\end{array}$ & Yao et al & Song et al & Song et al & Liu et al & Lyu et al & Hag \& Liu & $\begin{array}{l}\text { X. Zhang et } \\
\text { al }\end{array}$ \\
\hline $\begin{array}{l}\text { Publishe } \\
\text { d }\end{array}$ & 2016 & 2016 & 2016 & 2016 & 2016 & 2017 & 2017 & 2017 & 2018 & 2018 & 2019 & 2019 \\
\hline Channel & Multiple & Single & Single & Multiple & Single & $\begin{array}{l}\text { Multip } \\
\text { le }\end{array}$ & Multiple & Multiple & Multiple & Multiple & Multiple & Single \\
\hline
\end{tabular}

- Addresses scalability.

- It divides the signal into different time frames.

- Each frame is divided into several time slots, where each node is assigned to a time slot to transmit.

- The length of the time slot may vary, based on the needs of the node assigned to it.

- The main advantage of TDMA is reducing interference between nodes.

According to [13][28], the writer regarded the design of the MAC layer due to the progressively extensive application demands in VANETs, which one must consider the low-latency and high-reliability transmission specifications for security texts, as well as the high-throughput requirements for entertainment and service emails. The Author adopts a TDMA-based access system to provide vehicle contention-free transmission and guarantee message transmission reliability. Also embrace a system of contention-based negotiation to guarantee that cars using service channels are fair. There are few assumptions about the model before introducing the channel frame structure: First, each vehicle is equipped with a half-duplex transceiver that can only work on the $\mathrm{CCH}$ or SCHs simultaneously. Second, for inter-vehicle synchronization, GPS will provide an accurate UTC clock signal. [12], a channel frame structure shows a schematic diagram of one synchronization period channel frame structure. The $\mathrm{CCH}$ framework is split into the era of broadcasting and negotiation. The broadcast period consists of time slots of equal length, and the amount of slots will alter with traffic densities to enable the car to periodically broadcast status messages. The negotiation period is based on the system for back-off access to guarantee fairness between cars that access SCHs. The three-way handshake protocol is used during the negotiation period; the car can choose to access an accessible service channel each time a handshake protocol is finished. Therefore, the length of the SCHs will adapt to the results of the negotiations. When compared, the fresh system somewhat improves SCH's throughput. Existing MAC protocols based on TDMA may result in slot assignment collisions when multiple vehicle sets move with different speeds together. Contrary to this, intersections have the greatest need for reliable data communication to ensure the safety of driving. 
International Journal of Engineering and Advanced Technology (IJEAT) ISSN: 2249 - 8958, Volume-8 Issue-5C, May 2019 India.

\begin{tabular}{|c|c|c|c|c|c|c|c|c|c|c|c|c|}
\hline $\begin{array}{l}\text { Pure } \\
\text { TDMA }\end{array}$ & No & Yes & No & No & Yes & Yes & Yes & Yes & Yes & Yes & Yes & No \\
\hline $\begin{array}{l}\text { Merging } \\
\text { collision }\end{array}$ & $\begin{array}{l}\text { Solve } \\
\text { d }\end{array}$ & $\begin{array}{l}\text { Solve } \\
\text { d }\end{array}$ & Solved & Possible & Possible & $\begin{array}{l}\text { Possib } \\
\text { le }\end{array}$ & Possible & Possible & Posible & Solved & Possible & Possible \\
\hline $\begin{array}{l}\text { Access } \\
\text { collision }\end{array}$ & $\begin{array}{l}\text { Solve } \\
\mathrm{d}\end{array}$ & $\begin{array}{l}\text { Solve } \\
\text { d }\end{array}$ & Possible & Solved & Solved & $\begin{array}{l}\text { Solve } \\
\mathrm{d}\end{array}$ & Solved & Solved & Solved & Solved & Solved & Solved \\
\hline Mobility & High & High & High & High & Medium & High & High & High & High & High & High & Medium \\
\hline $\begin{array}{l}\text { Density } \\
\text { (scalability) }\end{array}$ & High & High & High & High & High & High & High & High & Medium & Medium & High & Medium \\
\hline $\begin{array}{l}\text { Broadcast } \\
\text { service }\end{array}$ & Yes & Yes & Yes & Yes & Yes & Yes & Yes & Yes & Yes & Yes & Yes & Yes \\
\hline $\begin{array}{l}\text { Mobility } \\
\text { model }\end{array}$ & $\begin{array}{l}\text { Highw } \\
\text { ay }\end{array}$ & $\begin{array}{l}\text { Highw } \\
\text { ay }\end{array}$ & $\begin{array}{l}\text { Highway/U } \\
\text { rban }\end{array}$ & Highway & Highway & $\begin{array}{l}\text { Highw } \\
\text { ay }\end{array}$ & Highway & Highway & Highway & Highway & Highway & Highway \\
\hline $\begin{array}{l}\text { Vehicular } \\
\text { traffic }\end{array}$ & $\begin{array}{l}\text { Bidirectio } \\
\text { nal }\end{array}$ & $\begin{array}{l}\text { Bidirectio } \\
\text { nal }\end{array}$ & N/A & $\begin{array}{l}\text { Bidirectio } \\
\text { nal }\end{array}$ & $\begin{array}{l}\text { Unidirecti } \\
\text { onal }\end{array}$ & $\begin{array}{l}\text { Unidirect } \\
\text { ional }\end{array}$ & $\begin{array}{l}\text { Bidirecti } \\
\text { onal }\end{array}$ & $\begin{array}{l}\text { Bidirecti } \\
\text { onal }\end{array}$ & $\begin{array}{l}\text { Unidirecti } \\
\text { onal }\end{array}$ & $\begin{array}{l}\text { Unidirecti } \\
\text { onal }\end{array}$ & $\begin{array}{l}\text { Unidirecti } \\
\text { onal }\end{array}$ & $\begin{array}{l}\text { Unidirecti } \\
\text { onal }\end{array}$ \\
\hline $\begin{array}{l}\text { Data } \\
\text { load }\end{array}$ & $\begin{array}{l}\text { High } \\
\text { load }\end{array}$ & $\begin{array}{l}\text { High } \\
\text { load }\end{array}$ & Medium & High load & High load & $\begin{array}{l}\text { High } \\
\text { load }\end{array}$ & $\begin{array}{l}\text { High } \\
\text { load }\end{array}$ & $\begin{array}{l}\text { High } \\
\text { load }\end{array}$ & High load & High load & High load & Medium \\
\hline $\begin{array}{l}\text { Control } \\
\text { overhead }\end{array}$ & High & High & Medium & High & Medium & $\begin{array}{l}\text { Mediu } \\
\mathrm{m}\end{array}$ & Medium & Medium & Low & Low & Medium & Medium \\
\hline $\begin{array}{l}\text { Transmission } \\
\text { range }\end{array}$ & $\begin{array}{l}\text { Mediu } \\
\mathrm{m}\end{array}$ & $\begin{array}{l}\text { Mediu } \\
\mathrm{m}\end{array}$ & Medium & Medium & Medium & High & High & High & Low & N/A & High & High \\
\hline $\begin{array}{l}\text { Multimedia } \\
\text { applications }\end{array}$ & Yes & No & No & Yes & No & Yes & Yes & Yes & Yes & Yes & Yes & No \\
\hline $\begin{array}{l}\text { Real-Time } \\
\text { applications }\end{array}$ & Yes & Yes & Yes & Yes & Yes & Yes & Yes & Yes & Yes & Yes & Yes & Yes \\
\hline $\begin{array}{l}\text { Positioning } \\
\text { System GPS }\end{array}$ & Yes & Yes & Yes & Yes & Yes & Yes & Yes & Yes & Yes & Yes & Yes & Yes \\
\hline $\begin{array}{l}\text { Time } \\
\text { Synchronizatio } \\
\mathrm{n}\end{array}$ & Yes & Yes & Yes & Yes & Yes & Yes & Yes & Yes & Yes & Yes & Yes & Yes \\
\hline $\begin{array}{l}\text { Simulato } \\
\mathrm{r}\end{array}$ & $\begin{array}{l}\text { MATL } \\
\text { AB }\end{array}$ & $\begin{array}{l}\mathrm{MOV} \\
\mathrm{E} / \mathrm{SU} \\
\mathrm{MO} / \\
\mathrm{NS} 23 \\
4\end{array}$ & MATLAB & $\begin{array}{l}\text { SUMO/ } \\
\text { MATLA } \\
\text { B }\end{array}$ & MATLAB & NS2 & NS3 & NS3 & SUMO & SUMO & N/A & OMNET++ \\
\hline
\end{tabular}

\section{Cluster based Time Division Multi Access (TDMA)}

VANET is based on the reliability of the Medium Access Control (MAC) protocol, according to [16], figure 3. VANET must provide reliable and timely delivery for a security application. Quality of service (QoS) requirement such as delivery delay and packet loss rate cannot be guaranteed under conventional MAC protocol, particularly under high vehicle mobility, heavy traffic conditions, frequent changes in network topology and high network density affecting timely delivery of critical safety applications [7]. Despite increasing vehicle density and transmission range, even if the $\mathrm{CH}$ moved out of the cluster without the need for cluster reconfiguration, the vehicles would still remain connected to the existing cluster for a long time. The approach enhanced the stability of the cluster. In addition, it significantly minimized the delay in broadcasting safety messages by using the worst-case scenario. Compared to the threshold-based approach, $\mathrm{CH}$ achieved a reduction of approximately 50 percent in the delay in transmitting safety messages to CMs. The process minimizes interference in adjacent clusters and delivered safety massages efficiently. It also provides stability to the cluster and minimizes overhead cluster. Only vehicles that move in the same direction and have the same road ID are considered to form a cluster group on a highway within a road segment. A message moving in a different direction from a neighboring vehicle is not considered and is ignored. The vehicles ' arrival rate is supposed to be a Poisson process.

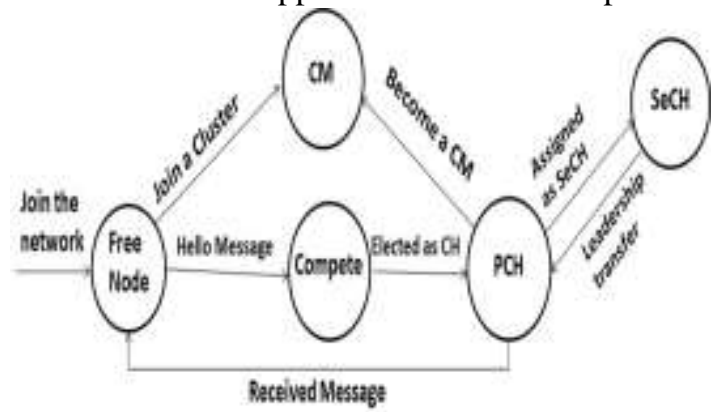

Figure 3: clustering Transition Model, [16]. 
According to [7][31], the standard IEEE $802.11 \mathrm{p}$ only provides VANETs with a contention-based MAC protocol while using an enhanced distributed channel access (EDCA) mechanism. However, due to the lack of request-to-send / clear-to-send (RTS / CTS) exchange, it does not provide an effective broadcast service with limited communication delay. Also, when the multiple nodes attempt to send their safety messages simultaneously, the probability of transmission collisions increases. MAC protocols based on Time Division Multiple Access (TDMA) such as ADHOC MAC and VeMAC protocol could solve the above problem. ADHOC MAC is a distributed TDMA-based MAC protocol that provides efficient broadcasting and service quality $(\mathrm{QoS})$ guarantees for inter-vehicle communication and solves hidden / exposed terminal problems caused by random access in multi-hop network architecture. Unlike the IEEE 802.11p standard, it is a single-channel protocol, not suitable for dedicated short-range communication (DSRC), which uses seven DSRC channels and allocates time slots based on vehicle direction to reduce vehicle-to-vehicle collisions. However, for the control channel $(\mathrm{CCH})$ and service channels (SCHs), it employs two half-duplex transceivers, respectively. Many contention-free TDMA MAC protocols have recently adopted cluster-based architecture because with the help of cluster head

$(\mathrm{CH})$ they can provide effective topology control, fair channel access within each cluster, and minimize intra-cluster and inter-cluster transmission collisions. This paper proposed an average time-based clustering algorithm for link expiration (ALET-CA), which takes into account multiple factors, such as relative distance and relative node velocity, and radius for transmission.

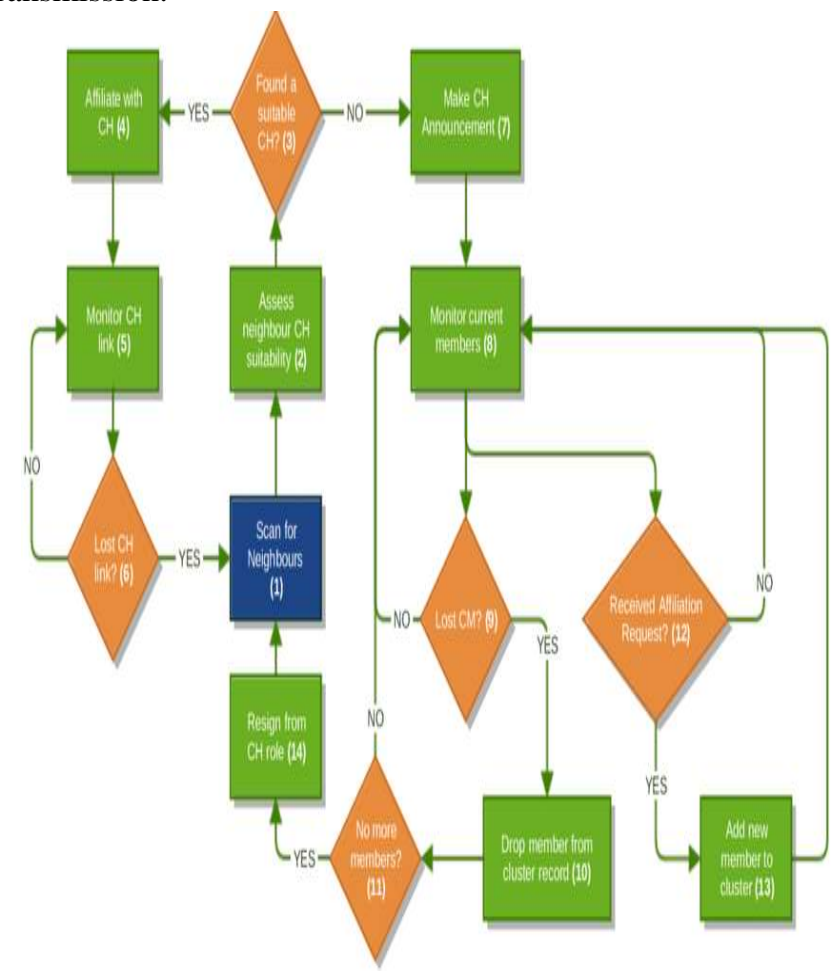

Figure 4: The basic flow of a clustering algorithm [32]

Network model is only for intra-vehicle clusters and inter-vehicle clusters. Because of its high speed and the dense building in the network, cluster structure is more suitable in VANET, according to [17][33]. Cluster algorithm is used to generate multiple clusters where the cluster head $(\mathrm{CH})$ with a maximum connectivity clustering algorithm selects the node with the highest adjacent nodes, but is not suitable for stable cluster structure, figure 4. Modifications in topology change node connectivity. The nodes used by the ALM clustering algorithm's mobility and location do not consider the node's relative position in the cluster structure. The relative node movement is not considered by adopting weighted

clustering algorithm. The current traffic load is not considered by a stable algorithm based VMaSC, which calculates the neighboring node speed function. The SWC and AMA-composed AMAC protocol uses clustering and access information to solve clustering problems for high-speed vehicles. The VeMAC protocol combines random access with fixed allocation access, and uses the technique of random selection to select time slots to reduce transmission collisions and then achieve high network throughput.

TDMA Assignment Algorithm

- Clusterhead based clustering scheme

- One transceiver on-board

- vehicles are equipped with GPS

- $1 \mathrm{CCH}$ (cch)

- $6 \mathrm{SCHs}(\mathrm{k})$

- $\mathrm{N}$ vehicles

- $\tau$ is the slot size in SCHs

- a mini-slot on the control channel

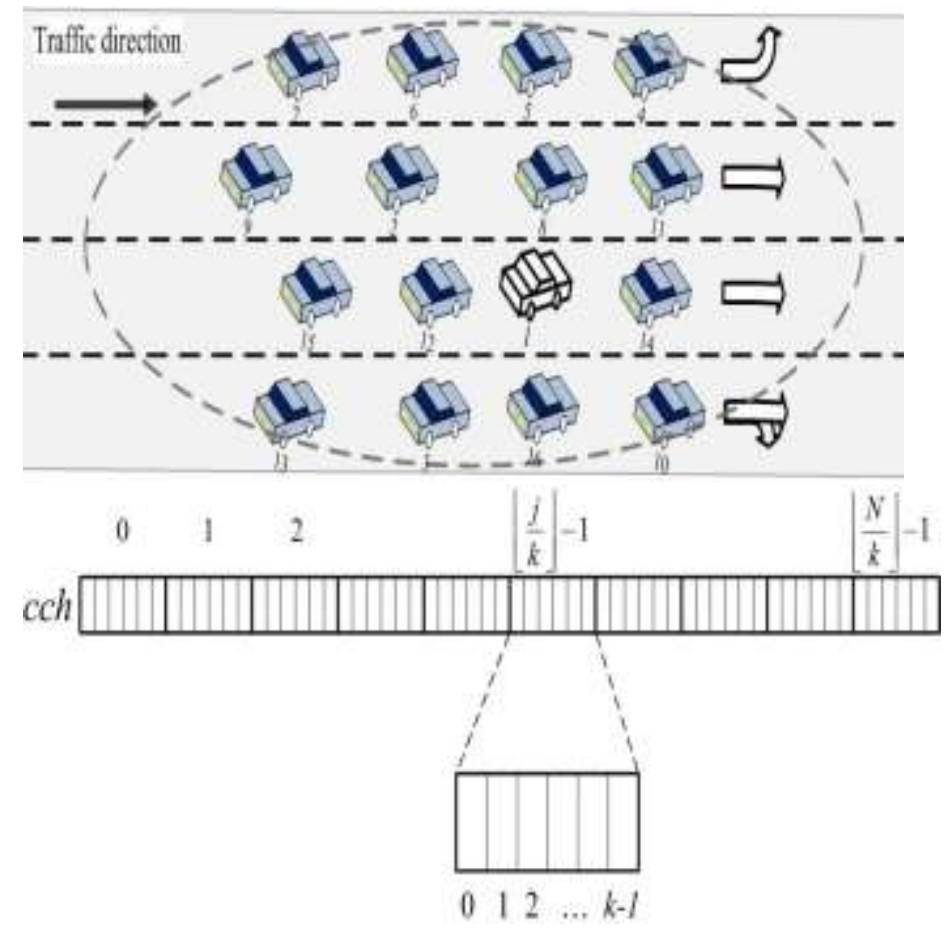

- channel $\mathrm{j} \bmod \mathrm{k}$ during time slot $[\mathrm{j} / \mathrm{k}] \mathrm{j}$; also, vehicle $\mathrm{j}$ owns the ordered pair $(\mathrm{j}$ and $\mathrm{k},[\mathrm{j} / \mathrm{k}] \mathrm{j})$

- The j-th mini-slot of slot ( [j/k] - $1 \bmod [\mathrm{N} / \mathrm{k}]$ on channel cch

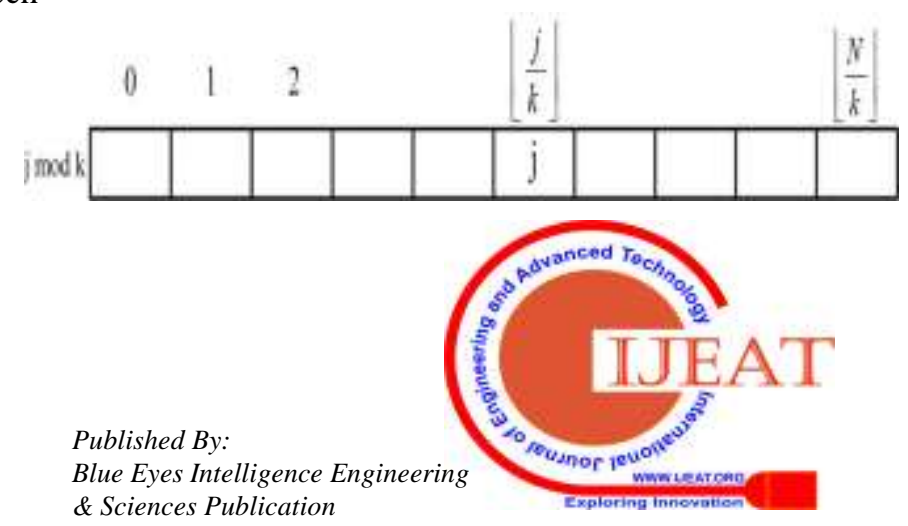


The Vehicle Ad-hoc Network (VANET) involves cars with specialized access points, according to [34]. It transmits and gets data from the Sensor Nodes (SNs) and environment to manage traffic loads. Destination routing, car velocity and direction management are therefore significant issues in VANETs. This document introduced the use of VANETS to hybridize Q-LEACH clustering based on FCM. The ideal CH was achieved from the group of SNs through this clustering. The data gathered by these $\mathrm{CHs}$ is transmitted to the near- $\mathrm{CH}$ highway side unit. The RSU-BS communication took place via the IEEE 802.11.p protocol. Based on the BS information, users know about the environment on the roadside. The performance of this FCM-Q LEACH-VANET was analyzed in terms of energy consumption, total packet transmission, network latency and performance. Results showed that the FCM-Q LEACH-VANET performs better than the IDVR protocol. The suggested technique has been introduced with distinct amount of SNs and 10 highway side units. The output of FCM-Q LEACH-VANET evaluated the VANET effectiveness with Dynamic VANET Routing Intersection (IDVR). There is currently an intensive research on the problems of reliability and scalability of the routing protocol across large urban VANETs.

Clustering can be used to improve the scalability and efficiency of VANET routing as it results in the production of hierarchical network structures by grouping cars together based on correlated spatial distribution and relative velocity. These organisations, in relation to the benefits of routing, can serve as the grounds for collision detection or congestion detection, information dissemination and entertainment applications. The [32], reviews the design choices taken when VANET-oriented clustering algorithms are created. It introduces a taxonomy of cluster head selection methods, cluster membership and cluster management issues, and identifies fresh directions and latest trends in the design of these algorithms. Also, methodologies for clustering performance validation are reviewed and a key shortcoming is identified as the lack of realistic modeling of vehicle channels. The significance of a strict and standardized performance evaluation system using realistic car channel models is demonstrated by [24].

TABLE 2: Qualitative comparison of TDMA-based MAC protocols in cluster-based network topology

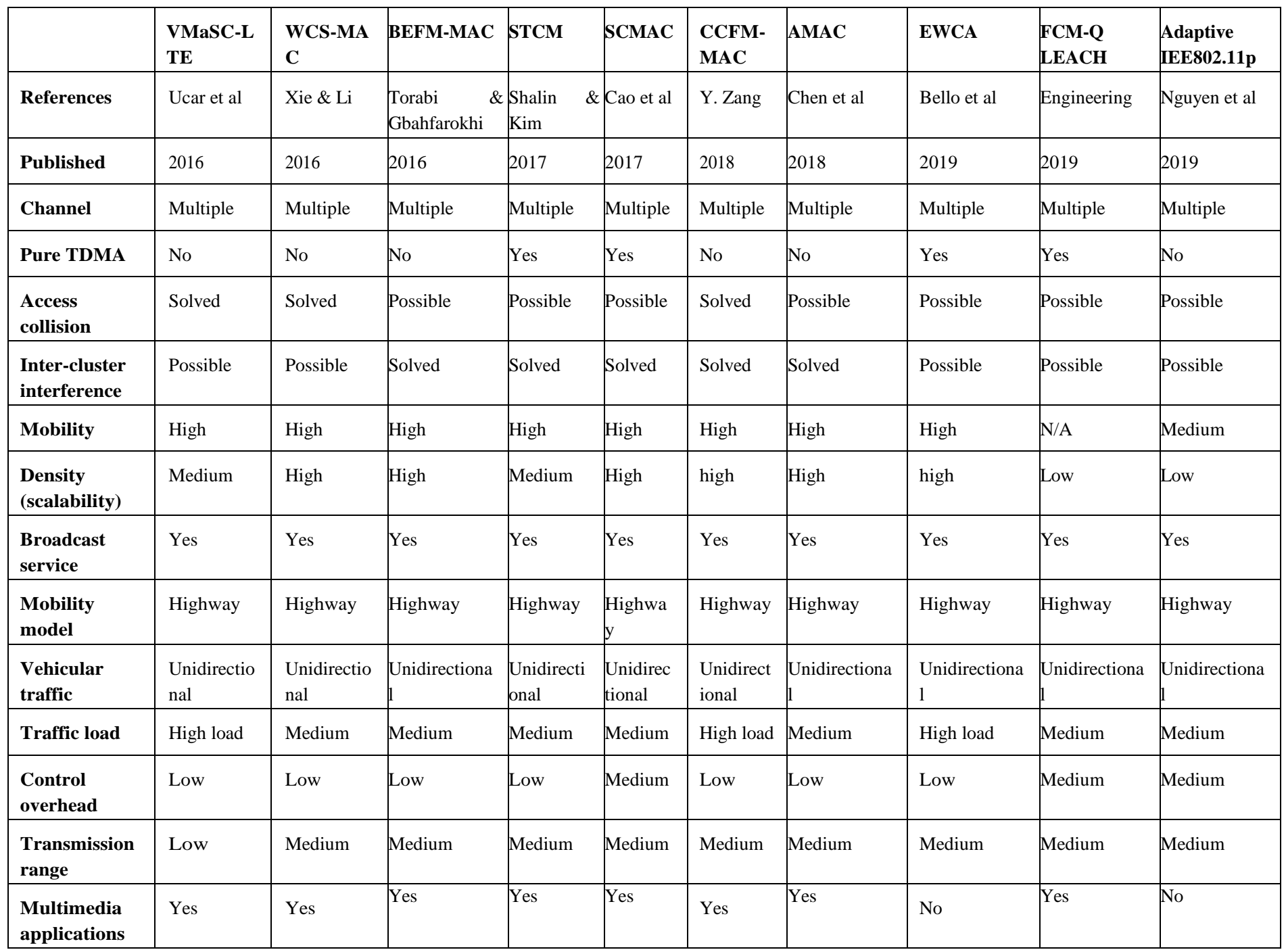


International Conference on Recents Advancements in Engineering and Technology (ICRAET-18) |15th and 16th March 2019|Siddhartha Institute of Technology \& Sciences, Telangana, India.

\begin{tabular}{|l|l|l|l|l|l|l|l|l|l|}
\hline $\begin{array}{l}\text { Real-Time } \\
\text { applications }\end{array}$ & Yes & Yes & Yes & Yes & Yes & Yes & Yes & Yes \\
\hline GPS System & Yes & No & Yes & Yes & Yes & Yes & Yes & No \\
\hline $\begin{array}{l}\text { Time } \\
\text { Synchronizati } \\
\text { on }\end{array}$ & Yes & Yes & Yes & Yes & Yes & Yes & Yes & Yes \\
\hline $\begin{array}{l}\text { Simulator } \\
\text { NS37SU }\end{array}$ & N/A & $\begin{array}{l}\text { SUMO, NS2 \& } \\
\text { MATLAB }\end{array}$ & Nos & $\begin{array}{l}\text { NS2 \& } \\
\text { SUMO MATLAB }\end{array}$ & SUMO, NS2 \& \\
MATLAB
\end{tabular}

\section{Hybrid TDMA/CSMA multi-channel MAC protocol}

As in [24][35][36], many packet types like HELLO packet, SWITCH packet, and WSA / RES / ACK packet are broadcast during the contention period. Therefore, because of the number of packets transmitted, there is a higher probability of collision. Thus, the overhead control will decrease the $\mathrm{CCH}$ throughput. A Hybrid TDMA / CSMA multi-channel MAC (HTC-MAC) protocol for VANETs is presented to solve the disadvantages of HER-MAC. Not only does HTC-MAC remove unnecessary overhead control, but it also improves the control channel throughput. Simulation and analysis demonstrate that HTC-MAC outperforms HER-MAC in the average number of time-slot nodes. However, when the node density is large, HTC-MAC needs a bigger ANC's payload size to transmit data to its neighbours. A centralized TDMA-based MAC protocol called CTMAC that used RSU as a vehicle channel coordinator within its communication range[37][9]. The ways in which slots are assigned and reused among the coverage fields of the RSU are intended to prevent accidents triggered by the issue of vehicle interference in overlapping regions. When the results of ADHOC and VeMAC MAC protocols were compared, CTMAC was able to provide a lower rate of access and merging collisions as well as the overhead needed to create and maintain TDMA schedules. CTMAC does not promote multichannel operation and the control channel's secure smulti-hop broadcasting service. The PTMAC protocol proposed to decrease the number of packet collisions, especially for encounter collisions. Potential collisions between cars could be identified, predicted, and then eliminated by intermediate cars before they actually happen [22]. The simulations show the protocol's effectiveness.
Unbalanced traffic densities will not degrade PTMAC, [19], since no slot partition is used. PTMAC is also suitable for handling four-way traffic under different traffic densities, unlike a few existing MAC protocols that work only for one way or two-way traffic scenarios. The results show that with the least number of collisions and the highest delivery rate, the PTMAC works best. Since ADHOC MAC enables a car to compete for any vacant slot without taking into account the nature of mobility of the cars, it is appropriate for only one-way traffic and its efficiency is significantly impacted by the enormous amount of crashes under such a four-way intersection situation. This is because not only does PTMAC eliminate collisions between vehicles from opposite directions, but it also prevents collisions from the same direction. Designing a new prediction-based TDMA MAC (PTMAC) protocol to reduce the likelihood of encounter collisions while maintaining high slot utilization and with very small additional overheads. Most collisions of the encounter can be predicted and potentially eliminated before they actually occur. The forecast is based on the data already supplied by the car to help apps related to safety.

- The freshly constructed PTMAC protocol is proven to be appropriate for two-way traffic and four-way junctions in metropolitan areas. Unbalanced densities of traffic will not degrade PTMAC's efficiency.

- $\quad$ By evaluating and comparing our PTMAC protocol to ADHOC MAC and even odd TDMA MAC, PTMAC demonstrates improved efficiency with lower

collisions and greater shipping rates for two-way and four-way intersection situations.

Table 3. Different adaptive IEEE 802.11p-based multi-channel MAC protocols.

\begin{tabular}{|l|l|l|l|l|l|l|}
\hline Reference & $\begin{array}{l}\text { Protocol } \\
\text { name }\end{array}$ & Interval divisions & Optimized object & Advantages & $\begin{array}{l}\text { Disadvantages } \\
\text { hed }\end{array}$ \\
\hline $\begin{array}{l}\text { V. Nguyen et } \\
\text { al }\end{array}$ & RCMAC & $\begin{array}{l}\text { Safety interval } \\
\text { WSA/ACK interval }\end{array}$ & $\begin{array}{l}\text { Safety Interval } \\
\text { WSA/ACK interval }\end{array}$ & $\begin{array}{l}\text { Improves time slot } \\
\text { acquisition through RSU } \\
\text { coordination }\end{array}$ & $\begin{array}{l}\text { All nodes in constant speed. } \\
\text { Not suitable for multi-hop }\end{array}$ & $\begin{array}{c}2016 \\
\text { Nguyen et al }\end{array}$ \\
\hline HTC-MAC & Safety interval & $\begin{array}{l}\text { Safety interval } \\
\text { WSA/ACK interval } \\
\text { Supports the various QoS } \\
\text { requairments }\end{array}$ & $\begin{array}{l}\text { Has a drawback in supporting } \\
\text { throughut- } \\
\text { non-safety application. }\end{array}$ \\
\hline
\end{tabular}




\begin{tabular}{|c|c|c|c|c|c|c|}
\hline Hadded et al & CTMAC & $\begin{array}{l}\text { Safety interval } \\
\text { Coordination control frame } \\
\text { interval }\end{array}$ & $\begin{array}{l}\text { Safety interval } \\
\text { WSA/ACK interval }\end{array}$ & $\begin{array}{l}\text { In a large area covered, it } \\
\text { avoid collision by } \\
\text { interference between vehicles } \\
\text { in overlapping region. }\end{array}$ & $\begin{array}{l}\text { Do not support multi-channel } \\
\text { operation. The high are equip } \\
\text { with RSU which are very } \\
\text { expensive }\end{array}$ & 2016 \\
\hline $\begin{array}{l}\text { Y. Nguyen et } \\
\text { al }\end{array}$ & $\begin{array}{l}\text { TDMA-CS } \\
\text { MA }\end{array}$ & $\begin{array}{l}\text { WSA/ACK interval } \\
\text { Safety interval }\end{array}$ & $\begin{array}{l}\text { Safety interval } \\
W S A \text { interval }\end{array}$ & $\begin{array}{l}\text { The length of the BF is not } \\
\text { uniform. Therefore, each } \\
\text { vehicle dynamically adjust } \\
\text { the BF length according to its } \\
\text { neighbor }\end{array}$ & $\begin{array}{l}\text { Collision between the two-hop } \\
\text { neighbors attempt to access } \\
\text { available time slot. }\end{array}$ & 2016 \\
\hline Jiang et al & PTMAC & $\begin{array}{l}\text { WSA/ACK interval } \\
\text { Safety interval }\end{array}$ & $\begin{array}{l}\text { Safety interval } \\
W S A \text { interval }\end{array}$ & $\begin{array}{l}\text { Potencial collision between } \\
\text { two-hop communication } \\
\text { range can be ditected by } \\
\text { immediate vehicle predicted } \\
\text { and eliminated before it } \\
\text { occur. Reduce number of } \\
\text { collision and has the high } \\
\text { delivery rate }\end{array}$ & $\begin{array}{l}\text { Based on prediction instead of } \\
\text { real world scenario. It do not } \\
\text { eliminate collision totally }\end{array}$ & 2016 \\
\hline Ucar et al & $\begin{array}{l}\text { VMaSC-LT } \\
\text { E }\end{array}$ & $\begin{array}{l}\text { Safety interval } \\
\text { WSA interval }\end{array}$ & $\begin{array}{l}\text { Safety interval } \\
W S A \text { interval }\end{array}$ & $\begin{array}{l}\text { It forward efficient data with } \\
\text { minimizing delay }\end{array}$ & $\begin{array}{l}\text { Is not applicable to urban traffic } \\
\text { scenario and path information of } \\
\text { vanet }\end{array}$ & 2016 \\
\hline Xie \& Li & WCS-MAC & $\begin{array}{l}\text { Safety Interval } \\
\text { WSA interval }\end{array}$ & $\begin{array}{l}\text { Safety and Safety } \\
\text { critical SCA interval } \\
\text { WSA interval }\end{array}$ & $\begin{array}{l}\text { It forward efficient data with } \\
\text { minimizing delay }\end{array}$ & $\begin{array}{l}\text { A time delay for } \mathrm{CH} \text { election } \\
\text { result in longer average total } \\
\text { transmission time of an SCA } \\
\text { sesson. Connection is set up } \\
\text { only between } \mathrm{CH} \text { and } \mathrm{CM}\end{array}$ & 2016 \\
\hline $\begin{array}{l}\text { Torabi \& } \\
\text { Gbahfarokhi }\end{array}$ & BEFM-MAC & $\begin{array}{l}\text { Safety interval, } \\
\text { WSA interval }\end{array}$ & $\begin{array}{l}\text { Safety and Safety } \\
\text { critical SCA interval } \\
\text { WSA interval }\end{array}$ & $\begin{array}{l}\text { It has a better performance in } \\
\text { terms of fairness and bandwidth } \\
\text { utilization. }\end{array}$ & $\begin{array}{l}\text { Inter-cluster communication is } \\
\text { not addressed. The collision } \\
\text { between nodes from different } \\
\text { cluster occur and the hidden } \\
\text { nodes collision }\end{array}$ & 2016 \\
\hline Shalin \& Kim & STCM & $\begin{array}{l}\text { Safety interval, } \\
\text { WSA interval }\end{array}$ & $\begin{array}{l}\text { Safety and Safety } \\
\text { critical SCA interval } \\
\text { WSA interval }\end{array}$ & $\begin{array}{l}\text { Enhance packet delivery } \\
\text { in } \mathrm{CCH} \text { and throughput } \\
\text { in } \mathrm{SCH}\end{array}$ & $\begin{array}{l}\text { Limited to inter-cluster } \\
\text { communication with limited } \\
\text { nodes }\end{array}$ & 2017 \\
\hline Cao et al & SCMAC & $\begin{array}{l}\text { Safety interval, } \\
\text { WSA interval }\end{array}$ & $\begin{array}{l}\text { Safety and Safety } \\
\text { critical SCA interval } \\
\text { WSA interval }\end{array}$ & $\begin{array}{l}\text { Enhance packet delivery } \\
\text { in } \mathrm{CCH} \text { and throughput } \\
\text { in } \mathrm{SCH} \text {. Achieves reliable and } \\
\text { scalable periodic beaconing in } \\
\text { vehicular environment. It solves } \\
\text { hidden terminal problems. }\end{array}$ & $\begin{array}{l}\text { The channel fading is ignored to } \\
\text { focus on the MAC layer } \\
\text { performance. The concurrent } \\
\text { broadcasting will cause } \\
\text { collision }\end{array}$ & 2017 \\
\hline Yao et al. ${ }^{42}$ & FCM-MAC & $\begin{array}{l}\text { Coordination Control Frame } \\
\text { interval WSA and safety } \\
\text { message RES interval }\end{array}$ & $\begin{array}{l}\text { WSA and } \\
\text { message }\end{array}$ & $\begin{array}{l}\text { High channel utilization. } \\
\text { Supports the reliability for safety } \\
\text { application. Allows safety and } \\
\text { non-safety messages transmitted } \\
\text { in a flexible way. }\end{array}$ & $\begin{array}{l}\text { Considers WSA and safety } \\
\text { messages with the same packet } \\
\text { arrival rate. }\end{array}$ & 2017 \\
\hline
\end{tabular}


International Conference on Recents Advancements in Engineering and Technology (ICRAET-18) |15th and 16th March 2019|Siddhartha Institute of Technology \& Sciences, Telangana, India.

\begin{tabular}{|c|c|c|c|c|c|c|}
\hline Song et al. ${ }^{41}$ & APDM & $\begin{array}{l}\text { ORP interval Safety and } \\
\text { WSA/ACK interval }\end{array}$ & $\begin{array}{l}\text { Safety and } \\
\text { WSA/ACK interval }\end{array}$ & $\begin{array}{l}\text { Reduces the safety packet } \\
\text { delay. Improves the system } \\
\text { throughput in VANETs. }\end{array}$ & $\begin{array}{l}\text { Once optimal node leaves the } \\
\text { neighborhood, the channel } \\
\text { access schedule is lost and } \\
\text { collision between messages will } \\
\text { occur. }\end{array}$ & 2017 \\
\hline Song et al. ${ }^{40}$ & EQMMAC & $\begin{array}{l}\text { Safety interval Vehicle } \\
\text { identification interval }\end{array}$ & WSA/ACK interval & $\begin{array}{l}\text { Provide the high saturation } \\
\text { throughput. Improves } \\
\text { transmission delay for } \\
\text { non-safety application }\end{array}$ & $\begin{array}{ll}\text { Vehicles } & \text { require two } \\
\text { transceivers. }\end{array}$ & 2017 \\
\hline Y. Zhang et al & $\begin{array}{l}\text { CCFM-MA } \\
\text { C }\end{array}$ & $\begin{array}{l}\text { Safety interval, } \\
\text { WSA interval }\end{array}$ & $\begin{array}{l}\text { Safety and } \begin{array}{l}\text { Safety } \\
\text { critical SCA }\end{array} \\
\text { WSA interval }\end{array}$ & $\begin{array}{l}\text { No packet collision during } \\
\text { the process of inter-cluster } \\
\text { and inter-cluster }\end{array}$ & $\begin{array}{l}\text { Limited to intra-cluster } \\
\text { communication with limited } \\
\text { nodes. Do not include RSU in } \\
\text { the process }\end{array}$ & 2018 \\
\hline Chen et al & AMAC & $\begin{array}{l}\text { Safety interval, } \\
\text { WSA interval }\end{array}$ & $\begin{array}{l}\text { Safety and } \\
\text { critical SCA } \\
\text { WSA interval }\end{array}$ & $\begin{array}{l}\text { Reduces transmission } \\
\text { collision and achieved } \\
\text { high throughput }\end{array}$ & $\begin{array}{l}\text { Uses half-duplex transmission } \\
\text { and do not includes RSU in the } \\
\text { process. In high way scenarios } \\
\text { courses break in transmission }\end{array}$ & 2018 \\
\hline Liu et al & MoMAC & $\begin{array}{l}\text { Safety interval, } \\
\text { WSA interval }\end{array}$ & $\begin{array}{lrr}\begin{array}{l}\text { Safety and } \\
\text { critical }\end{array} \text { SCA } & \text { interval } \\
\text { WSA interval }\end{array}$ & $\begin{array}{l}\text { It assign time slot according } \\
\text { to road topology and lane } \\
\text { distribution on road }\end{array}$ & $\begin{array}{l}\text { I } \mathrm{V} 2 \mathrm{~V} \text { communication every } \\
\text { vehicle need to periodically } \\
\text { broadcast their status and turn } \\
\text { signal status to all neighbors } \\
\text { within one-hop. There is no } \\
\text { efficient slot assignment for } \\
\text { uneven traffics }\end{array}$ & 2018 \\
\hline Liu et al & $\mathrm{ABC}$ & $\begin{array}{l}\text { Safety interval, } \\
\text { WSA interval }\end{array}$ & $\begin{array}{l}\text { Safety and Safety } \\
\text { critical SCA interval } \\
\text { WSA interval }\end{array}$ & $\begin{array}{l}\text { Efficient beacon rate to avoid } \\
\text { a rear-end collision based on } \\
\text { individual estimates }\end{array}$ & $\begin{array}{l}\text { TDMA must reduce energy } \\
\text { waste in the contention } \\
\text { protocol and with limited } \\
\text { stability adaptability. Hard to } \\
\text { dynamic change from frame } \\
\text { size or slots assignment when } \\
\text { new nodes join }\end{array}$ & 2018 \\
\hline $\mathrm{X}$. Zhang et al & BB-MAC & $\begin{array}{l}\text { Safety interval, } \\
\text { WSA interval }\end{array}$ & $\begin{array}{l}\text { Safety and Safety } \\
\text { critical SCA interval } \\
\text { WSA interval }\end{array}$ & $\begin{array}{l}\text { It reduces collision and } \\
\text { speed-up time slot } \\
\text { acquisition }\end{array}$ & $\begin{array}{l}\text { Is only limited to medium } \\
\text { density of vehicle nodes }\end{array}$ & 2019 \\
\hline Engineering & $\begin{array}{l}\text { FCM-Q } \\
\text { LEACH }\end{array}$ & $\begin{array}{l}\text { Safety interval, } \\
\text { WSA interval }\end{array}$ & $\begin{array}{lrr}\text { Safety and } & \text { Safety } \\
\text { critical SCA interval } \\
\text { WSA interval }\end{array}$ & $\begin{array}{lr}\text { it enhances network } \\
\text { performance, especially } \\
\text { betwee } \mathrm{CH} \text { and } \mathrm{RSU}\end{array}$ & $\begin{array}{l}\text { It do not work on selection of } \\
\mathrm{CH} \text { in cluster network because } \\
\text { the choice is based on trust } \\
\text { degree. Transport of packet } \\
\text { using IEEE802.11p from RSU } \\
\text { to BS i.e. contention based is } \\
\text { not suitable for multi-hop }\end{array}$ & 2019 \\
\hline
\end{tabular}




\begin{tabular}{|c|c|c|c|c|c|c|}
\hline Nguyen et al & $\begin{array}{l}\text { Adaptive } \\
\text { IEEE } \\
802.11 \mathrm{p}\end{array}$ & $\begin{array}{l}\text { Safety interval } \\
\text { WSA/ACK interval }\end{array}$ & $\begin{array}{l}\text { Safety interval } \\
\text { WSA/ACK interval }\end{array}$ & $\begin{array}{l}\text { Improve saturated } \\
\text { throughput, adapt to amount } \\
\text { of traffic data and ensure } \\
\text { safety package transmission }\end{array}$ & $\begin{array}{l}\text { Not suitable for multi-hop } \\
\text { communication. When } \mathrm{CH} \text { move } \\
\text { out of their cluster, channel } \\
\text { access schedule is lost and } \\
\text { collision between messages occur }\end{array}$ & 2019 \\
\hline Bello et al. & EWCA & $\begin{array}{l}\text { Safety interval, } \\
\text { WSA interval }\end{array}$ & $\begin{array}{l}\text { Safety and Safety } \\
\text { critical SCA interval } \\
\text { WSA interval }\end{array}$ & $\begin{array}{lcr}\text { Minimize } & \text { interference in } \\
\text { adjacent } & \text { clusters. Provide } \\
\text { efficient delivery of } & \text { safety } \\
\text { messages. Provide } & \text { cluster } \\
\text { stability and minimizes } & \text { cluster } \\
\text { overhead, and maintenance }\end{array}$ & $\begin{array}{l}\text { A messages from neighboring } \\
\text { vehicles moving in different } \\
\text { direction is not considered, due } \\
\text { to merging amongst the } \\
\text { adjacent cluster. Uses poison } \\
\text { process to arrival rate of } \\
\text { vehicle' }\end{array}$ & 2019 \\
\hline Hag \& Liu & VeSOMAC & Safety interval, & $\begin{array}{l}\text { Safety and Safety critical } \\
\text { SCA interval WSA } \\
\text { interval }\end{array}$ & $\begin{array}{l}\text { It can operate in synchronize } \\
\text { and in asynchronies mode. } \\
\text { Improve TCP throughput } \\
\text { in this protocol }\end{array}$ & $\begin{array}{l}\text { Vehicles require two transceivers. } \\
\text { Unbounded delay in the delivery } \\
\text { of safety messages. }\end{array}$ & 2019 \\
\hline
\end{tabular}

VANET: vehicular ad hoc network; MAC: medium access control; WSA: Wireless Access in Vehicular Environment Service Advertisement; ACK: Acknowledgment; SCHI: service channel interval; QoS: quality of service; $\mathrm{CCH}$ : control channel; RES: Reservation; $\mathrm{CH}$ : control head; $\mathrm{CM}$ : control member

\section{CONCLUSSION}

The standard IEEE 802.11p only provides VANETs with a contention-based MAC protocol while using an enhanced distributed channel access (EDCA) mechanism. However, due to the lack of request-to-send / clear-to-send (RTS / CTS) exchange, it does not provide an effective broadcast service with limited communication delay. Also, when the multiple nodes attempt to send their safety messages simultaneously, the probability of transmission collisions increases. MAC protocols based on Time Division Multiple Access (TDMA) such as ADHOC MAC and VeMAC protocol could solve the above problem. ADHOC MAC is a distributed TDMA-based MAC protocol that provides efficient broadcasting and service quality (QoS) guarantees for inter-vehicle communication and solves hidden / exposed terminal problems caused by random access in multi-hop network architecture. Unlike the IEEE $802.11 \mathrm{p}$ standard, it is a single-channel protocol, not suitable for dedicated short-range communication (DSRC), which uses seven DSRC channels and allocates time slots based on vehicle direction to reduce vehicle-to-vehicle collisions. However, for the control channel $(\mathrm{CCH})$ and service channels ( $\mathrm{SCHs})$, it employs two half-duplex transceivers, respectively. Many contention-free TDMA MAC protocols have recently adopted cluster-based architecture because with the help of cluster head $(\mathrm{CH})$ they can provide effective topology control, fair channel access within each cluster, and minimize intra-cluster and inter-cluster transmission collisions. In table 5, gives detail analysis laveraging the applications of different TDMA protocols leveraging the VANET uptil date. The advantages and disadvantages are clearly stated and uniquely presented in figure 1,2 and 3. The analysis suggested for VANETs to guarantee that all vehicle have sufficient time to send safety messages without collisions and to decrease the end-to-end delay and the loss ratio of packets.

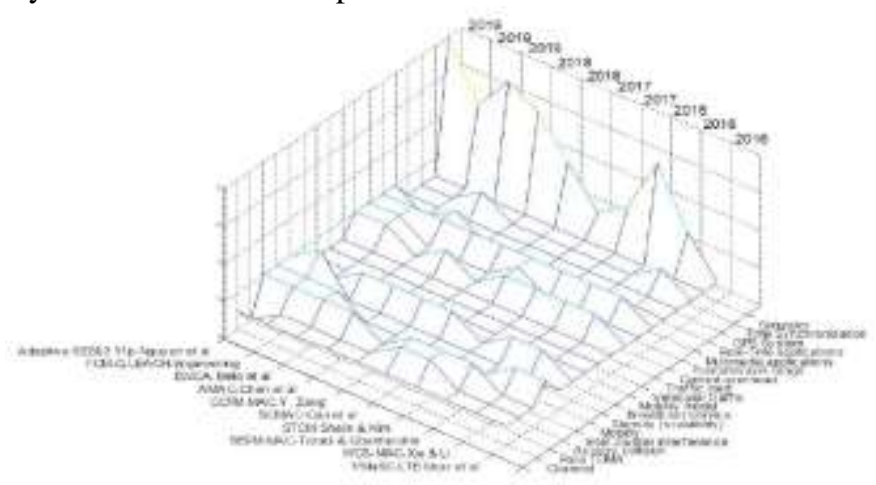

Figure 5: The number of TDMA-based MAC protocols proposed for each year.

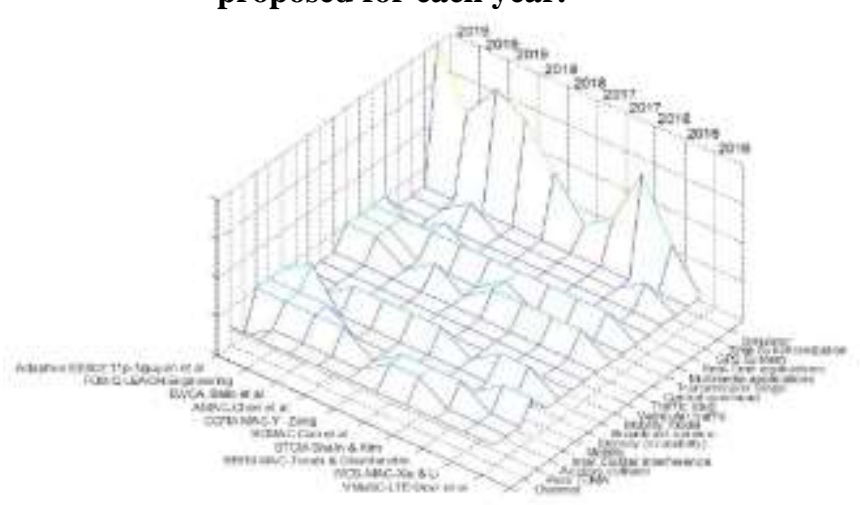

Figure 6: The number of TDMA-based MAC protocols proposed for each year 


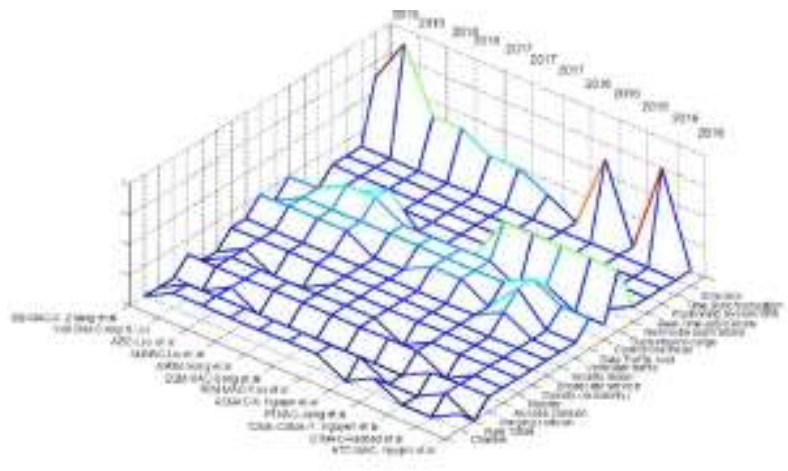

Figure 7: The number of TC-MAC protocols proposed for each year

Future work:

- Use multi-channel DSRC band to facilitate spatial reuse of channel resources to develop a contention-less scheme based on TDMA that contains unbounded delay.

- The RSU capable of listening to all broadcast messages and doing traffic condition statistics on each segment of the road and then using their time slots to broadcast up-to-date slot allocation scheme.

- $\mathrm{A} \mathrm{CH}$ in a cluster-based TDMA-MAC with the responsibility of allocating a slice of time to their $\mathrm{CMs}$ to reduce energy wasted.

- An average time-based clustering algorithm for link expiration, which takes into account multiple factors, such as relative distance and relative node velocity, and radius for transmission. Network model is only for intra-vehicle clusters and inter-vehicle clusters.

\section{REFERENCES}

1.V. Nguyen, O. T. T. Kim, T. N. Dang, and C. S. Hong, "Improving time slot acquisition through RSU's coordination for TDMA-based MAC protocol in VANETs," Int. Conf. Inf. Netw., vol. 2016-March, pp. 406-411, 2016.

2. G. Luo, J. Li, L. Zhang, Q. Yuan, Z. Liu, and F. Yang, "SdnMAC: A Software-Defined Network Inspired MAC Protocol for Cooperative Safety in VANETs," IEEE Trans. Intell. Transp. Syst., vol. 19, no. 6, pp. 2011-2024, 2018.

3. P. Murkya, J. Singh, and A. Bhatia, "A Topology Independent TDMA-based MAC protocol for Vehicular Networks," 2019 11th Int. Conf. Commun. Syst. Networks, vol. 2061, pp. 407-409, 2019.

4. F. Lyu et al., "DBCC: Leveraging Link Perception for Distributed Beacon Congestion Control in VANETs," IEEE Internet Things J., vol. 5, no. 6, pp. 4237-4249, 2018.

5. E. Daknou, N. Tabbane, and M. Thaalbi, "A MAC multi-channel scheme based on learning-automata for clustered VANETs," Proc. - Int. Conf. Adv. Inf. Netw. Appl. AINA, vol. 2018-May, pp. 71-78, 2018.

6. D. Huiming, Z. Xin, and Y. Dacheng, "Research on multichannel transmission of security information in MAC layer based on zoom and forward in VANETs," Cluster Comput., vol. 8, pp. 1-6, 2018.

7. Y. Zhang et al., "A Clustering-Based Collision-Free Multichannel MAC Protocol for Vehicular Ad Hoc Networks," 2018 IEEE 88th Veh. Technol. Conf., no. 2016, pp. 1-7, 2018.

8. P. (Global K. Simoneau et al., "Open Systems Interconnection Handbook," ARPN J. Eng. Appl. Sci., vol. 4, no. 4, pp. 935-960, 2018.

9. M. Hadded, P. Muhlethaler, A. Laouiti, and L. A. Saidane, "A centralized TDMA based scheduling algorithm for real-time communications in vehicular ad hoc networks," 2016 24th Int. Conf. Software, Telecommun. Comput. Networks, SoftCOM 2016, pp. 1-6, 2016.

10. M. Hadded, P. Muhlethaler, A. Laouiti, and L. A. Saidane, "TDMA-aware routing protocol for multi-hop communications in Vehicular Ad Hoc Networks," IEEE Wirel. Commun. Netw. Conf. WCNC, pp. 1-6, 2017.

10. N. Shahin and Y. T. Kim, "Scalable TDMA cluster-based MAC (STCM) for multichannel vehicular networks," 19th Asia-Pacific Netw. Oper. Manag. Symp. Manag. a World Things, APNOMS 2017, pp. 13-18, 2017.

12.Y. Sun, L. Xu, Y. Tang, and W. Zhuang, "Traffic Offloading for Online Video Service in Vehicular Networks: A Cooperative Approach," IEEE Trans. Veh. Technol., vol. 67, no. 8, pp. 7630-7642, 2018.

13. G. H. Alsuhli, A. Khattab, and Y. A. Fahmy, "Double-Head Clustering for Resilient VANETs," Wirel. Commun. Mob. Comput., vol. 2019, pp. 1-17, 2019.

14.C. Song, G. Tan, C. Yu, N. Ding, and F. Zhang, "APDM: An adaptive multi-priority distributed multichannel MAC protocol for vehicular ad hoc networks in unsaturated conditions," Comput. Commun., vol. 104, pp. 119-133, 2017.

15. L. Smith, "Dedicated Short Range Communication DSRC ) Statewide Guidance Summary of Research and Design Considerations Version 1.0," no. November 2018, 2018.

16.A. Bello, T. Id, R. Noor, R. Salleh, C. Chembe, and M. Oche, "Enhanced weight-based clustering algorithm to provide reliable delivery for VANET safety applications," pp. 1-19, 2019.

17.W. Chen, J. Jia, X. Du, Y. Zhang, and K. Liu, "A Clustering-Based Adaptive Multiple Access Protocol for Vehicular Ad Hoc Networks," 2018 IEEE Int. Conf. Commun. Syst., no. 2016, pp. 463-467.

18.Y. Cao, H. Zhang, D. Wu, and D. Yuan, "OGCMAC: A Novel OFDM Based Group Contention MAC for VANET Control Channel," IEEE Trans. Wirel. Commun., vol. 16, no. 9, pp. 5796-5809, 2017.

19. N. Torabi and B. S. Ghahfarokhi, "A bandwidth-efficient and fair CSMA/TDMA based multichannel MAC scheme for V2V communications," Telecommun. Syst., vol. 64 no. 2, pp. 367-390, 2017.

20.K. Tanuja, T. M. Sushma, M. Bharathi, and K. H. Arun, "A survey on VANET technologies," Int. J. Comput. Appl., vol. 121, no. 18, pp. 1-9, 2015.

21.D. Hossen, "Application of Dedicated Short-Range Communication within M-Commerce and Intelligent Transportation Services, and its global adaptation using RFID technology," no. July, 2016.

22. X. Jiang and D. H. C. Du, "PTMAC: A prediction-based TDMA MAC protocol for reducing packet collisions in VANET," IEEE Trans. Veh. Technol., vol. 65, no. 11, pp. 9209-9223, 2016.

23.Z. S. Houssaini, I. Zaimi, M. Oumsis, and S. E. A. Ouatik, "Comparative study of routing protocols performance for vehicular Ad-hoc networks,” Int. J. Appl. Eng. Res., vol. 12, no. 13, pp. 3867-3878, 2017.

24.S. Ucar, S. C. Ergen, and O. Ozkasap, "Multihop-Cluster-Based IEEE 802.11p and LTE Hybrid Architecture for VANET Safety Message Dissemination," IEEE Trans. Veh. Technol., vol. 65, no. 4, pp. 2621-2636, 2016. 
25. A. U. Haq and K. Liu, "Review of TDMA-Based MAC protocols for vehicular Ad Hoc networks," Int. Conf. Commun. Technol. Proceedings, ICCT, vol. 2019-Octob, pp. 459-467, 2019.

26. X. Zhang, X. Jiang, and M. Zhang, "A black-burst based time slot acquisition scheme for the hybrid TDMA/CSMA multichannel MAC in VANETs," IEEE Wirel. Commun. Lett., vol. 8, no. 1, pp. 137-140, 2019.

27. A. Yang, J. Weng, N. Cheng, J. Ni, X. Lin, and X. Shen, "DeQoS Attack: Degrading Quality of Service in VANETs and its Mitigation," IEEE Trans. Veh. Technol., vol. PP, no. c, pp. 1-1, 2019.

28. Z. Liu, L. Zhang, W. Ni, and I. B. Collings, "A Cross-Layer MAC Aware Pseudonym (MAP) Scheme for the VANET," 2018 IEEE Glob. Commun. Conf., pp. 1-6, 2019.

29.V. D. Nguyen, T. Z. Oo, T. T. Khanh, C. S. Hong, and E. N. Huh, "A comparison of interval division methods in adaptive IEEE 802.11p-based multi-channel medium access control protocols for vehicular ad hoc networks," Int. J. Distrib. Sens. Networks, vol. 15, no. 2, 2019.

30.C. Song, G. Tan, and C. Yu, "An efficient and QoS supported multichannel MAC protocol for vehicular ad hoc networks," Sensors (Switzerland), vol. 17, no. 10, pp. $1-28,2017$.

31.M. A. Labiod, M. Gharbi, F. X. Coudoux, P. Corlay, and N Doghmane, "Enhanced adaptive cross-layer scheme for low latency HEVC streaming over Vehicular Ad-hoc Networks (VANETs)," Veh. Commun., vol. 15, pp. 28-39, 2019.

32. C. Cooper, D. Franklin, M. Ros, F. Safaei, and M Abolhasan, "A Comparative Survey of VANET Clustering Techniques," IEEE Commun. Surv. Tutorials, vol. 19, no. 1, pp. 657-681, 2017.

33.Y. Cao, H. Zhang, X. Zhou, and D. Yuan, "A Scalable and Cooperative MAC Protocol for Control Channel Access in VANETs," IEEE Access, vol. 5, pp. 9682-9690, 2017.

34. R. V. C. Engineering, "An Efficient Cluster based Routing Protocol using Hybrid FCM-Q LEACH for Vehicular Ad Hoc Networks," vol. 14, no. 7, pp. 1604-1612, 2019.

35.D. N. M. Dang, H. N. Dang, V. Nguyen, Z. Htike, and C. S. Hong, "HER-MAC: A hybrid efficient and reliable MAC for vehicular Ad Hoc networks," Proc. - Int. Conf. Adv. Inf. Netw. Appl. AINA, pp. 186-193, 2014.

36. A. Di Maio, R. Soua, M. R. Palattella, and T. Engel, "ROADNET: Fairness- and throughput-enhanced scheduling for content dissemination in VANETs," 2018 IEEE Int. Conf. Commun. Work. ICC Work. 2018 - Proc., pp. 1-6, 2018.

37. Q. Mao, P. Yue, M. Xu, Y. Ji, and Z. Cui, "OCTMAC: A VLC based MAC protocol combining optical CDMA with TDMA for VANETs," IEEE CITS 2017 - 2017 Int. Conf. Comput. Inf. Telecommun. Syst., pp. 234-238, 2017.

38. J. Xie and C. Li, "Weight Clustering Based TDMA-MAC Scheme in VANET," Autom. - J. Control. Meas. Electron. Comput. Commun., vol. 57, no. 1, 2016.

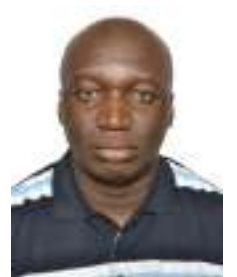

\section{AUTHOR'S PROFILE}

Siman Emmanuel, PhD Student, Department of Computer Science, Faculty of Computing, Universiti Teknologi Malaysia. Lecturer Computer Science, Federal University Wukari, Taraba, Nigeria.

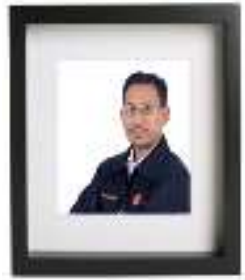

Ismail Fauzi Isnin, $\mathrm{PhD}$, Senior Lecturer, Department of Computer Science, Faculty of Computing, Universiti Teknologi Malaysia. Doctor of Philosophy, University of Plymouth, United Kingdom, • Research: A Study on Wireless Communication Error Performance and Path Loss Prediction..Mobile Adhoc Network; Robotic

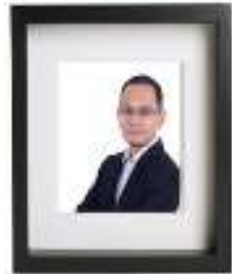

Mohd Murtadha Mohamad, Senior lecturer,Faculty of Computing, $\mathrm{PhD}$ in Electrical, Universiti Teknologi Malaysia, Heriot-Watt University UK. Research: Robotic;Artifficial Intelligent; Motion Planing; Ubiquitius Posisioning; Underwater Acoustic Sensor Network 